\title{
Tiotropium bromide is effective for severe asthma with noneosinophilic phenotype
}

\section{To the Editor:}

Although currently available asthma medications are very effective in the majority of cases, there remains a subgroup for which disease control is difficult. Anticholinergics have long been used to treat asthma, although their current role in therapy is supplementary [1]. Tiotropium bromide, a recently developed anticholinergic, is a long-acting bronchodilator with a well-established effectiveness for treating chronic obstructive pulmonary disease [2]. Although some subgroups of asthmatics seem to respond better to anticholinergics, the pathophysiological features of these responders have yet to be established [3,4]. Previous studies that aimed to identify asthma subgroups which respond better to anticholinergics have suggested the following clinical features: patients with nocturnal symptoms, chronic asthma showing concurrent fixed airway obstruction, intrinsic asthma with longer duration of disease and nonatopic asthma [1,5]. The objective of the present study was to determine the characteristics of asthmatics which show good responses to tiotropium bromide.

We investigated the efficacy of tiotropium bromide in 17 asthmatic patients followed in an outpatient setting at Hiroshima University Hospital (Hiroshima, Japan). Consecutive patients were selected with severe persistent asthma diagnosed and classified according to Global Initiative for Asthma guidelines [6]. The study was approved by the local ethics committee and written informed consent was obtained from all subjects.

Subject characteristics are shown in table 1. All patients were treated with inhaled corticosteroids equivalent to 800 $1,600 \mu \mathrm{g} \cdot \mathrm{day}^{-1}$ of budesonide. Other anti-asthma medications were also prescribed, including $5-20 \mathrm{mg} \cdot \mathrm{day}^{-1}$ of oral corticosteroid $(23.5 \%)$. All subjects had tried a long-acting $\beta_{2^{-}}$ agonist (LABA) but six (35.3\%) stopped administration due to ineffectiveness or adverse events. The remaining subjects continued using LABA.

Induced sputum was obtained prior to tiotropium bromide administration. Induced sputum was collected for 5 min after each 5-min inhalation of 3, 4 and 5\% hypertonic saline for a total of $30 \mathrm{~min}$. Lung function tests were performed before and 4 weeks after tiotropium administration. The efficacy of tiotropium bromide was assessed through the change in forced expiratory volume in one second $(\triangle \mathrm{FEV} 1) . \triangle \mathrm{FEV} 1$ following addon therapy with tiotropium bromide was analysed using the Wilcoxon signed-rank test. Associations between measured variables were examined using Spearman's rank correlation test.

Tiotropium bromide administration for 4 weeks was well tolerated by all subjects and FEV1 improved significantly $(p=0.001)$.
There were no significant correlations between $\triangle \mathrm{FEV} 1$ and demographic or clinical variables including age, sex, body mass index, smoking history, atopic status, disease duration, and use of particular anti-asthmatic drugs, such as LABA and leukotriene receptor antagonist (data not shown).

The percentages of eosinophils in induced sputum were inversely correlated with $\triangle \mathrm{FEV} 1$ (fig. 1a). The proportions of neutrophils were positively correlated with $\triangle \mathrm{FEV} 1$ (fig. 1b). We also analysed subjects who had never smoked $(n=8)$ and former or current smokers $(n=9)$ separately because smoking has been associated with changes in cell types of induced sputum [7]. In addition, restriction to subjects who had never smoked could exclude the confounding effects of COPD, which may be complicated in smoking asthmatics. The analysis of eight subjects who had never smoked showed comparable correlations between eosinophils or neutrophils and $\triangle \mathrm{FEV} 1$.

The results of this investigation suggest associations between responsiveness to tiotropium bromide and types of inflammatory cells in the induced sputum of patients with severe persistent asthma treated with moderate-to-high doses of

$\begin{array}{lc}\text { TABLE 1 } & \\ \text { Subjects } \mathbf{n} & \\ \text { Males } \mathbf{n} & 17 \\ \text { Age yrs } & 7 \\ \text { BMI kg } \mathbf{m}^{-2} & 1.0 \pm 11.5(45-78) \\ \text { Smoking history } \mathbf{n} & 23.7 \pm 3.3 \\ \quad \text { Never-smoker } & \\ \text { Ex-smoker } & 8 \\ \text { Current smoker } & 5 \\ \text { Atopy } & 4 \\ \text { Disease duration yrs } & 9(52.9) \\ \text { Asthma control test score } & 22.2 \pm 16.6 \\ \text { Anti-asthmatic drugs use } & 18.4 \pm 4.3 \\ \text { Inhaled corticosteroid } & \\ \text { Oral corticosteroid } & 17(100) \\ \text { LABA } & 4(23.5) \\ \text { Theophylline } & 11(64.7) \\ \text { Leukotriene receptor antagonist } & 6(35.3) \\ \text { FVC L } & 11(64.7) \\ \text { FEV1 L } & 2.83 \pm 0.80 \\ & 1.68 \pm 0.69\end{array}$

Data are presented as mean \pm SD (range), mean \pm SD or $n$ (\%), unless otherwise stated. BMI: body mass index; LABA: long-acting $\beta_{2}$-agonist; FVC: forced vital capacity; FEV1: forced expiratory volume in one second. 

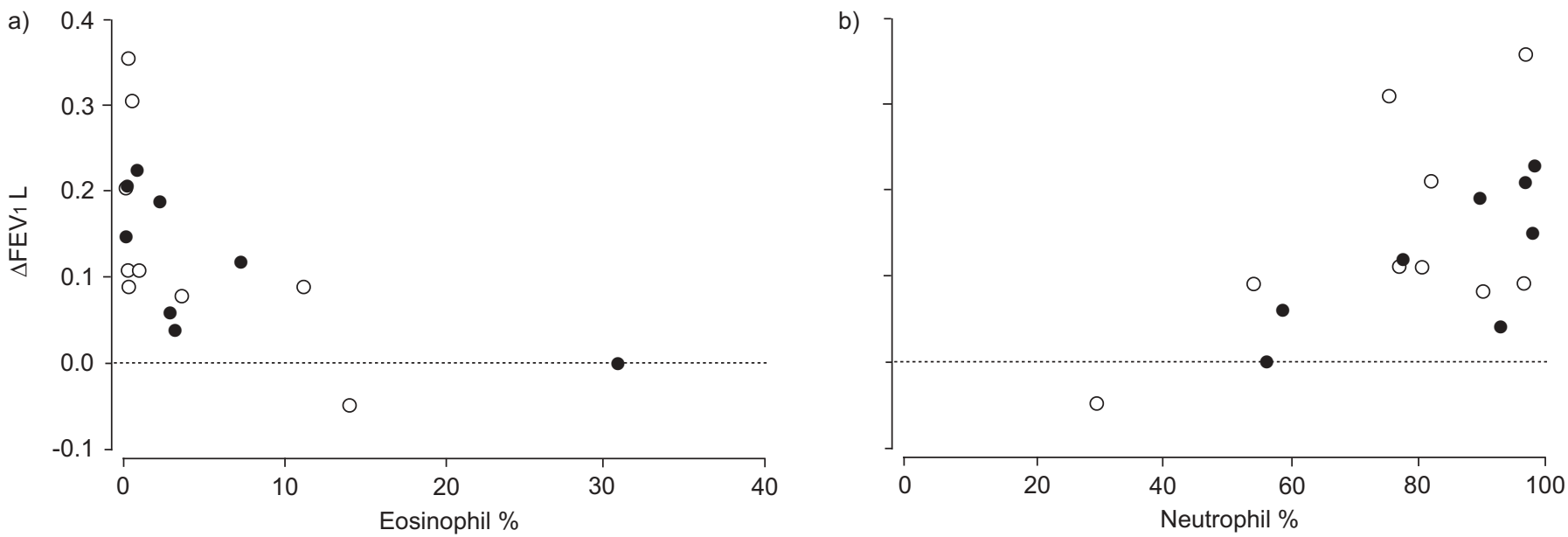

FIGURE 1. Spearman rank correlations $\left(r_{s}\right)$ between the change in forced expiratory volume in one second $\left(\Delta F E V_{1}\right)$ after 4 weeks of tiotropium bromide administration and a) eosinophil percentages or b) neutrophil percentages in induced sputum. Eosinophil and neutrophil percentages were determined prior to tiotropium bromide administration. In all subjects a) $r_{S}=-0.669, p=0.003$ and $\left.b\right) r_{S}=0.540, p=0.025$. In smokers a) $r_{S}=-0.706, p=0.034$ and $\left.b\right) r_{S}=0.361, p=0.339$. In nonsmokers a) $r_{S}=-0.762$. $\mathrm{p}=0.028$ and $b) r_{\mathrm{S}}=0.762, p=0.028$. $\bigcirc$ : smokers; $\bullet$ : nonsmokers.

inhaled corticosteroids and other anti-asthma agents. Comparable results from nonsmoking and smoking asthmatics indicate a rationale for using tiotropium bromide to treat severe asthma with a noneosinophilic sputum profile.

The differences in clinical responses to anti-asthma drugs might be associated with the heterogeneous nature of asthma $[1,8]$. Evidence indicates considerable heterogeneity of airway inflammation in severe asthma [9]. The most well-recognised pattern is noneosinophilic asthma, possibly associated with neutrophil influx and activation [9]. The associations between induced sputum cells and clinical responses to anti-asthma drugs are well documented: an eosinophilic profile was reported to be associated with a better response to corticosteroids [8]. The results of this preliminary study indicate that the induced sputum profile could also help to distinguish tiotropium bromide responders in severe persistent asthmatics: a noneosinophilic sputum profile is associated with a better response to tiotropium bromide. This observation warrants validation by further clinical investigation.

\section{H. Iwamoto*\#, A. Yokoyama", N. Shiota*\#, H. Shoda*\#, Y. Haruta, N. Hattori and N. Kohno*}

*Dept of Molecular and Internal Medicine, Graduate School of Biomedical Sciences, Hiroshima University, Hiroshima, and ${ }^{\#}$ Dept of Hematology and Respiratory Medicine, Kochi University, Kochi, Japan.

\section{SUPPORT STATEMENT}

This study was partly supported by Grants-in-Aid for Scientific Research from the Japan Society for the Promotion of Science.

\section{STATEMENT OF INTEREST}

None declared.

\section{REFERENCES}

1 Westby M, Benson M, Gibson P. Anticholinergic agents for chronic asthma in adults. Cochrane Database Syst Rev 2004; 3: CD003269.

2 Rabe KF, Hurd S, Anzueto A, et al. Global strategy for the diagnosis, management, and prevention of COPD: GOLD executive summary. Am J Respir Crit Care Med 2007; 176: 532-555.

3 O'Connor BJ, Towse LJ, Barnes PJ. Prolonged effect of tiotropium bromide on methacholine-induced bronchoconstriction in asthma. Am J Respir Crit Care Med 1996; 154: 876-880.

4 Fardon T, Haggart K, Lee DK, Lipworth BJ. A proof of concept study to evaluate stepping down the dose of fluticasone in combination with salmeterol and tiotropium in severe persistent asthma. Respir Med 2007; 101: 1218-1228.

5 Gross NJ. Anticholinergic agents in asthma and COPD. Eur J Pharmacol 2006; 533: 36-39.

6 Global Initiative for Asthma (GINA) Executive Committee, Global Strategy for Asthma Management and Prevention. GINA 2006. www.ginasthma.com Date last updated: November 2006. Date last accessed: October 16, 2007.

7 Chalmers GW, MacLeod KJ, Thomson L, Little SA, McSharry C, Thomson NC. Smoking and airway inflammation in patients with mild asthma. Chest 2001; 120: 1917-1922.

8 Haldar P, Pavord ID. Noneosinophilic asthma: a distinct clinical and pathologic phenotype. J Allergy Clin Immunol 2007; 119: 1043-1052.

9 Gibson PG, Simpson JL, Saltos N. Heterogeneity of airway inflammation in persistent asthma: evidence of neutrophilic inflammation and increased sputum interleukin-8. Chest 2001; 119: 1329-1336. 